\title{
Estudos discursivos foucaultianos: questões de método para análise de discursos
}

\author{
Foucauldian discourse studies - method questions for discourse analysis
}

\author{
Pedro NAVARRO \\ Universidade Estadual de Maringá (UEM/CNPq)
}

https://orcid.org/0000-0003-3267-4985

\begin{abstract}
RESUMO: Este artigo apresenta contribuições do pensamento de Michel Foucault para os estudos discursivos da linguagem, realizando-se um encaminhamento mais teórico que analítico, visto que problematiza o chamado método arqueogenealógico, que é mobilizado para a compreensão de alguns fatos de discurso que parecem, em parte, dar conta de evidenciar a produtividade de termos-conceituais desse método. Para tanto, traça-se um fio condutor em torno de três interrogações: precisamos ainda nos filiar à chamada Análise de Discurso francesa? Michel Foucault propôs ou não um método de análise das formações discursivas sobre as quais se debruçou para descrever suas regras de formação? O último Foucault ainda é um arqueologista? A descrição das práticas discursivas da parresia e do cuidado de si permite que façamos uma leitura discursiva dos enunciados para deles identificar as regras de formação, as posições de sujeito e as condições nas quais se exerce a função enunciativa que assegura e define as práticas do cuidado e da verdade e os dispositivos de saber-poder postos em funcionamento nos processos de subjetivação.
\end{abstract}

PALAVRAS-CHAVE: Michel Foucault. Método arqueogenealógico. Cuidado de si. Verdade. Sujeito.

\begin{abstract}
This study aims to show Michel Foucault's contributions regarding the language discursive studies. It is mainly based on a theoretical approach, rather than an analytical one since the first problematizes the so-called archeogenealogical method, which is employed to comprehend some discourse facts that seem, in part, to be able to highlight the productivity of conceptual terms of this method. To do so, it draws a thread around three questions, first, is it still necessary we join the so-called French discourse analysis? Second, did Michel Foucault propose a method of analyzing the discursive formations he worked on to describe their formation rules? And last, is Foucault still an archeologist? The description of the discursive practices of parrhesia and care of the self allows us to engage in a discursive reading of the utterances to identify the formation rules, the subject positions, and the conditions in which the enunciative function. Besides that, it ensures and defines both care and truth practices, and the knowledge-power devices are engaged in the processes of subjectification.
\end{abstract}

KEYWORDS: Michel Foucault. Archeogenealogical method. Care of the self. Truth. Subject.

\section{Introdução}

Meu propósito, neste texto, é refletir sobre algumas importantes contribuições da perspectiva arqueogenealógica para os estudos discursivos da linguagem, tendo em vista os ganhos que tivemos com as discussões e as análises que Michel Foucault faz e que foram introduzidas no campo da Linguística teórica, no final dos anos 1990, por um 
grupo de professores e pesquisadores que, com a criação e o fortalecimento de seus grupos particulares ao longo desses anos, criaram, em 2018, o GT Estudos Discursivos Foucaultianos, filiado à Associação Nacional de Pós-Graduação e Pesquisa em Letras e Linguística (ANPOLL).

Parece-me oportuno constar, também, que as reflexões que seguem foram motivadas pelas comemorações dos 50 anos de publicação da obra "A arqueologia do Saber", ocorridas em 2019, em especial por dois eventos ${ }^{1}$, nos quais tive a oportunidade de realizar alguns apontamentos sobre a presença desse filósofo na análise de discursos que vem, cada vez mais, ganhando corpo e fortalecendo-se por meio das pesquisas realizados pelos grupos filiados ao GT.

O que apresento nas páginas seguintes é um texto com um encaminhamento mais teórico que analítico, visto que intento problematizar o chamado método arqueogenealógico, que será mobilizado para a compreensão de alguns fatos de discurso que me parecem, em parte, dar conta de evidenciar a produtividade de termosconceituais que retiro desse método. Desse modo, procuro traçar o fio condutor de minhas inquietações em torno de três interrogações, sendo uma mais geral e para a qual não destinarei mais que algumas poucas linhas, já me direcionando para as duas seguintes e mais específicas, nas quais vou me deter demoradamente:

1. Precisamos ainda nos filiar à Análise de Discurso francesa?

2. Michel Foucault propôs ou não um método de análise das formações discursivas sobre as quais se debruçou para descrever suas regras de formação?

3. O último Foucault ainda é um arqueologista?

\section{Precisamos ainda nos filiar à Análise de Discurso francesa?}

Creio que não. Criamos um GT intitulado Estudos Discursivos Foucaultianos, logo os pesquisadores filiados não necessitam mais remontar às chamadas "três épocas" da Análise de Discurso (PÊCHEUX, 1990a) para chegar até Foucault e suas contribuições a esse construto teórico materialista. Não cabem, em uma mesma pesquisa, noções tais como: discurso como efeito de sentido, interdiscurso, sujeito interpelado, inconsciente e formações ideológicas e imaginárias, quando tal pesquisa se propõe a fazer incursões pelas regiões onde o poder encontra o saber (FOUCAULT,

\footnotetext{
${ }^{1}$ Arqueologia do Saber (M. FOUCAULT) 50 anos: questões inevitáveis. Universidade Estadual Paulista (Unesp), campus de Araraquara, 12 e 13 de junho de 2019 / (Re)ler a Arqueologia do Saber hoje nos estudos discursivos da linguagem: 50 anos. Universidade Estadual de Maringá (UEM), de 14 a 16 de outubro de 2019.
} 
1988; 2006a), e o sujeito é, nesse espaço, subjetivado e, quiçá, ensejaria algum gesto de controle sobre si, a ponto de se transfigurar, mediante uma prática de liberdade, por mais tímida e cerceada que seja (FOUCAULT, 1995; 2010a). Ou enfrentamos a região cinza da genealogia para escavar os saberes que ali nos atravessam ou fazemos outro tipo de análise discursiva. Não vejo opção ou meio termo, tampouco é uma questão de escolha entre um caminho mais adequado que outro. É escolher um caminho e suportar o abandono do outro. Em algum momento, teremos de responder a uma pergunta basilar: qual nossa concepção de sujeito, de discurso e de história?

Alguém poderia objetar, argumentando ser possível conciliar essas duas perspectivas discursivas. Acho que sim, desde que elas estejam coordenadas, não justapostas. Observemos, contudo, a proposta arqueológica que Foucault (1972a) apresenta logo na introdução de "A arqueologia do Saber", quando mostra que o problema que se formula à história geral, em contraposição à visão global, é determinar as formas de relação que podem ser descritas entre diferentes séries, os sistemas verticais que tais séries podem formar, bem como qual o jogo de correlações e/ou de dominações entre elas.

É nesse sentido que considero a impossibilidade de fazer caminhar, a par e passo, as perspectivas teórico-metodológicas advindas de Pêcheux e de Foucault, sob a pena de se fazerem rápidas aproximações entre as noções por eles elaboradas, estabelecer algo como uma relação sem problematizações entre uma concepção psicanalítica de sujeito constituído pelos "esquecimentos 1 e 2" (PÊCHEUX, 1990b) e uma visão filosófica de sujeito que necessita das "utopias" (FOUCAULT, 2013) para que seu corpo e sua alma possam viver, também, em outros espaços e tempos (FOUCAULT, 1984), somente para citar essas possibilidades de descrição da subjetividade humana. Estaríamos lidando com objetos de discurso (sujeito, discurso e poder) cujos escopos são formulados a partir de paradigmas ${ }^{2}$ distintos.

Sem os esquecimentos 1 e 2 e sem as utopias, não há sujeito, mas as implicações desses dois postulados para as análises precisam ser enfrentadas, constantemente interrogadas, a partir da concepção de discurso em funcionamento, o que requer entradas discursivas no arquivo sob investigação, guiadas por perguntas que não têm a mesma base epistemológica. A insistência em empreender uma análise das relações de poder-saber que se projetam e produzem sujeitos, buscando uma

\footnotetext{
${ }^{2}$ Emprego esse termo, apesar da distinção e de alguns pontos de contato entre episteme e paradigma, respectivamente formulados por Foucault (2007) e por Kuhn (2013).
} 
identificação de pesquisador com a vertente francesa de Análise de Discurso, pode levar esse mesmo pesquisador a cair na justaposição de noções, sem considerar que uma possa excluir a outra e sem se dar conta da inexistência de correlações necessárias para a configuração de um mesmo campo de estudos.

A consideração da natureza dispersa dos elementos de uma mesma formação discursiva, tal como delineado por Foucault (1972a), poderia, em tese, advogar a favor da ideia de que os objetos mencionados ganham condições de existência pela prática discursiva na qual se constituíra esse campo maior identificado como Análise de Discurso; contudo, justamente por se ter em conta que esse campo poderia ser isolado e descrito como tal, é que o pesquisador teria de enfrentar "conceitos que se diferem em estrutura e regras de utilização, que se ignoram ou se excluem uns aos outros e que não podem entrar na unidade de uma arquitetura lógica” (FOUCAULT, 1972a, p. 42).

Se quiséssemos fazer algo semelhante a uma arqueogenealogia dos estudos em análise de discursos desenvolvidos nos programas de pós-graduação do país, deveríamos começar isolando e reorganizando essas duas grandes séries (estudos pêcheuxtianos e foucaultianos) para, em seguida, fazer aparecer os encadeamentos entre seus objetos, suas modalidades enunciativas, seus conceitos e estratégias; colocá-los em relação e observar como aí eles se comportam, em face dos objetivos de pesquisa, das perguntas e do corpus de análise.

\section{Michel Foucault propôs ou não um método de análise das formações discursivas sobre as quais se debruçou para descrever suas regras de formação?}

Creio que possamos formular possíveis respostas, a partir de algumas passagens encontradas nas obras citadas em minha argumentação. Meu esforço é no sentido de acentuar que somos muito mais chamados a buscar subsídios teóricos e metodológicos em Michel Foucault que responder se esse autor propôs ou não um método para fazer sua descrição dos saberes e dos efeitos de poder vinculados a esses saberes.

A esse respeito, Machado (1988) chama a atenção para a importância do método arqueológico, por ser uma ferramenta que nos leva a refletir sobre as Ciências Humanas, na medida em que produz saberes sobre o homem. Outro ponto para iniciar minhas reflexões sobre a identidade de Foucault autor e a sua abordagem acerca do sujeito, do saber e do poder vem desta advertência feita, também, por Machado: 
[...] o método de análise proposto por Foucault é geralmente conhecido como "arqueologia do saber". O que talvez pouca gente saiba é que esta denominação é um ponto de chegada, não um ponto de partida; é o resultado de um processo, também histórico, em que, para se definir, a arqueologia procurou sempre se situar em relação à epistemologia. Daí o privilégio que conferimos a essa relação (MACHADO, 1988, p. 10).

Feito isso, deter-me-ei em algumas citações em que observamos Foucault falar de si, na medida em que explica a arqueologia que empreende dos saberes. Dessas passagens, interrogamos a existência de, pelo menos, três identidades de autor que se amalgamam na teoria.

\subsection{As "identidades" de Michel Foucault e seu empreendimento sobre a experiência do sujeito em relação ao saber, ao poder e à estética da existência}

Podemos encontrar, em textos e em entrevistas concedidas por Michel Foucault, momentos em que ele tenta se definir a partir de suas obras ou recusa determinadas identidades a ele atribuídas. Faço menção, por exemplo, às entrevistas que concedeu a Shigehiko Hasumi (gravada em Paris, no dia 13/10/77), a Jacques Rancière (publicada em Les révoltes logigues, . $^{\circ}$ 4, inverno de 1977) e a estudantes de Los Angeles (uma discussão muito informal transcrita por Grant Kim, a partir de uma gravação realizada em maio de 1975, na Founders Room do Pomone College, em Claremont, publicada em 1978).

Antes de mais nada, problematizo o uso da palavra identidade no título desta subseção, levando em conta o sentido burlesco e paródico que justifica seu emprego. Em outros termos, conduzir esta seção tendo como entrada a identidade do autor Michel Foucault só é possível se não associarmos uma pálida individualidade a identidades marcadamente reais do passado. De um ponto de vista genealógico, não podemos nos esquecer de que a história serial faz sucumbir as continuidades e emergir as dispersões de sujeito:

[...] esta identidade, bastante fraca contudo, que nós tentamos assegurar e reunir sob uma máscara, é apenas uma paródia: o plural a habita, almas inumeráveis nela disputam: os sistemas se entrecruzam e se dominam uns aos outros" (FOUCAULT, 1979, p. 34).

Talvez possamos, com isso, fazer aparecer todas as descontinuidades que atravessam esse lugar de autoria de Michel Foucault e de sua obra.

Primeira identidade: Foucault seria um filósofo que propôs um método de análise? 
Em uma das citações, Foucault é enfático ao dizer que não dispõe de um método que se aplicaria, igualmente, a domínios diferentes. Nosso olhar situado no presente para a obra desse filósofo nos faz ver que esses domínios seriam o da loucura, o da economia, o da delinquência, o da sexualidade e o do governo dos vivos, para citar apenas esses.

\section{Assim, somos expostos a}

[...] um mesmo campo de objetos, um domínio de objetos que procuro isolar, utilizando instrumentos encontrados ou forjados por mim, no exato momento em que faço minha pesquisa, mas sem privilegiar de modo algum o problema do método. [...] Não tenho uma teoria geral e tampouco tenho um instrumento certo. Eu tateio, fabrico, como posso, instrumentos que são destinados a fazer aparecer objetos. Os objetos são um pouquinho determinados pelos instrumentos bons ou maus fabricados por mim (FOUCAULT, 2006b, p. 229).

Segunda identidade: Foucault é um historiador?

Eis a resposta: "Meu projeto não é de fazer um trabalho de historiador, mas descobrir por que e como se estabelecem relações entre os acontecimentos discursivos. Se faço isso, é com o objetivo de saber o que somos hoje" (FOUCAULT, 2006b, p. 258).

Mesmo não querendo assumir esse status de historiador, mantém um profícuo diálogo com os historiadores da escola dos Annales (VEYNE, 1998; DOSSE, 2001). O que devemos reter desse diálogo para nossas análises é que essa identidade de autor nos mobiliza a pôr em funcionamento dois importantes aspectos. Primeiro, se Foucault propõe um método, este concebe a história como o acontecimento, que, por sua vez, é marcado por táticas e por estratégias de hierarquização próprias de um jogo.

Nessa direção, uma das tarefas do tipo de análise de discursos que empreendemos é fazer emergir os diversos núcleos de poder, nos quais estão incluídos os homens simples. As descrições enunciativas voltam-se, assim, para práticas discursivas cotidianas, o que impõe uma análise histórico-discursiva que deve

[...] seguir o pulular desses procedimentos que, muito longe de ser controlados ou eliminados pela administração panóptica, se reforçaram em uma proliferação ilegitimada, desenvolvidos e insinuados nas redes de vigilância, combinados segundo táticas ilegíveis, mas estáveis a tal ponto que constituem regulações cotidianas e criatividades sub-reptícias que se ocultam somente graças aos dispositivos e aos discursos, hoje atravancados, da organização observadora (DE CERTEAU, 1994, p. 175).

O segundo aspecto relaciona-se com a historicidade dos discursos. Courtine (1994) e Maldidier e Guilhaumou (1994) postulam que a linguagem se constitui no 
tecido da memória, uma vez que os "lugares de memória" (NORA, 1985; 1993) dos discursos são eles mesmos. Assim, a linguagem é a modalidade de existência histórica essencial da memória, seja ela coletiva, histórica ou social. Em vista disso, uma análise que parte da hipótese de que as redes sociais, por exemplo, funcionam como um dos lugares de refúgio da memória tem por objetivo observar, no discursivo textual, os indícios de um trabalho da memória na materialidade desses discursos.

Terceira identidade: Foucault é um empirista?

Então essa camada de objetos, ou melhor, essa camada de relação, é difícil de apreender; e como não há teorias gerais para apreendê-las, eu sou, se quiserem, um empirista cego [...] Eu tateio, fabrico, como posso, instrumentos que são destinados a fazer aparecer objetos (FOUCAULT, 2006b, p. 229).

Em sua “A arqueologia do Saber", um dos objetos que o filósofo faz aparecer é a figura do delinquente, a partir da descrição das práticas que convergem para a produção dessa objetivação, sobre as quais me detenho mais adiante. Sobre Foucault ser um empirista cego, consideremos as análises que faz do poder disciplinar, momento em que a genealogia intervém como uma espécie de um incremento para arqueologia, e isso nos impulsiona a investigar o papel decisivo das instituições sociais e de suas práticas. Como informa Foucault,

Eu diria em duas palavras o seguinte: a arqueologia seria o método próprio da análise das discursividades locais, e a genealogia, a tática que faz intervir, a partir dessas discursividades locais assim descritas, os saberes dessujeitados que daí se desprendem (FOUCAULT, 2010b, p. 11).

Nessa perspectiva, o mecanismo disciplinar vai configurar-se como um instrumento para a análise do funcionamento do poder sobre os indivíduos:

Não se deve, acho eu, conceber o indivíduo como uma espécie de núcleo elementar, átomo primitivo, matéria múltipla e muda na qual viria aplicar-se, contra a qual viria bater o poder, que submeteria os indivíduos ou os quebrantaria. Na realidade, o que faz que um corpo, gestos, discursos, desejos sejam identificados e constituídos como indivíduos, é precisamente isso um dos efeitos primeiros do poder. Quer dizer, o indivíduo não é o vis-à-vis do poder; é, acho eu, um dos seus efeitos primeiros. O indivíduo é um efeito do poder e é, ao mesmo tempo, na mesma medida em que é um efeito seu, seu intermediário: o poder transita pelo indivíduo que ele constituiu (FOUCAULT, 2010b, p. 26).

O método arqueogenealógico permite, pois, uma compreensão histórica de como certos mecanismos infinitesimais do poder consolidaram-se e estabeleceram-se como práticas de um saber sobre o homem, por corolário, sobre seu corpo. 


\subsection{O discurso como prática: elementos constituintes e norteadores da pesquisa arqueogenealógica}

A respeito das citações nas quais Foucault, ao mesmo tempo em que fala sobre si, diz também sobre seu empreendimento teórico e analítico, detenho-me na distinção entre história serial e história global, na noção de discurso como prática e nas regras de formação dos objetos, a meu ver três importantes elementos implicados nos recortes que selecionei para o fio condutor que venho traçando até este momento.

Quais aspectos caracterizariam essa perspectiva histórica da qual Foucault se vale para se contrapor à história tradicional?

Primeiro aspecto, o fato de que a história global tem como projeto "reconstituir a forma de conjunto de uma civilização, o princípio de uma sociedade, a significação comum a todos os fenômenos de um período", como se houvesse uma lei que explicasse a coesão de dado período, "uma única e mesma forma de historicidade [que] prevaleça sobre as estruturas econômicas" (FOUCAULT, 1972a, p. 17).

Já a perspectiva da história geral ou serial nos coloca diante da ideia de que não vivemos uma única temporalidade. Os estudos em desenvolvimento e aqueles concluídos por integrantes do grupo de pesquisa ${ }^{3}$ que coordeno (NAVARRO, 2015b, 2018; BAZZA, 2018; BAZZA; NAVARRO, 2019; SANCHES; NAVARRO, 2019; POLLA, 2018) têm mostrado que, em relação ao objeto de discurso velhice, não haveria um fenômeno único de conjunto, mas uma pluralidade de temas, de modalidades enunciativas e de domínio de memória, haja vista que nem todos os sujeitos da terceira e quarta idades se subjetivam da mesma forma em relação aos dispositivos de podersaber que pesam sobre eles.

Partindo da premissa de que a história serial não acomodaria elementos justapostos e independentes, os objetos de discurso sob investigação pelo mirante da arqueogenealogia impõem a realização de um trabalho que nos conduz a determinar que formas de relação podem ser descritas, por exemplo, entre a economia, as instituições, as religiões, as ciências e as literaturas, e se existe um sistema vertical entre essas séries. Esse trabalho descritivo dos enunciados efetivamente ditos ou escritos pode dar a conhecer o funcionamento de um jogo de correlações e/ou de predomínio de uma série enunciativa sobre outras. Somos, por esse método, constantemente interpelados a

\footnotetext{
${ }^{3}$ GEF - Grupo de Estudos Foucaultianos da UEM/ CNPq.
} 
considerar "em que conjuntos distintos certos elementos podem figurar simultaneamente" (FOUCAULT, 1972a, p. 18).

Quais seriam esses elementos? Em "História da loucura", por exemplo, Foucault (1972b) faz surgir a loucura como objeto de poder-saber, e somos levados a acompanhar este indivíduo, que é o louco, como um elemento de dispersão que se constitui entre e no jogo de correlações e/ou de dominância, bem como figura em conjuntos distintos de séries históricas, com suas regras de formação:

Na Histoire de la folie, tratei de uma formação discursiva cujos pontos de escolha teóricos eram bastante fáceis de serem demarcados, cujos sistemas conceituais eram relativamente pouco numerosos e sem complexidade, cujo regime enunciativo, enfim, era bastante homogêneo e monótono; em compensação, o problema era a emergência de todo um conjunto de objetos, muito enredados e complexos; tratava-se de descrever, antes de tudo, a formação desses objetos, para demarcar, em sua especificidade, o conjunto do discurso psiquiátrico (FOUCAULT, 1972a, p. 72).

Nesse sentido, assumir a tarefa de analisar discursos, estando sob o mirante de uma história serial, é, como Foucault (1972a, p. 18) insiste, fazer desdobrar "o espaço da dispersão", o que nos coloca na contramão de uma história global, que cinge todos os fenômenos em torno de um centro único. Talvez, por isso, meu incômodo inicial com o uso do sintagma "Análise de Discurso francesa" para referir a todos os trabalhos cujo objeto é o discurso e seu enunciador.

Segundo aspecto da história geral (serial) que se contrapõe à história global (tradicional): a noção de descontinuidade, tão cara às análises empreendidas por Foucault, ainda em sua fase arqueológica:

Em suma, a história do pensamento, dos conhecimentos, da filosofia, da literatura, parece multiplicar as rupturas e buscar todos os arrepios da continuidade, enquanto que a história propriamente dita parece apagar, em benefício das estruturas sem labilidade, a irrupção dos acontecimentos (FOUCAULT, 1972a, p. 12).

A descontinuidade é, também, o instrumento que lhe permite distinguir, quando se volta para a Antiguidade Clássica, as mudanças históricas em relação à cultura do cuidado de si. Tendo como foco a subjetividade que se constitui pelo retorno do sujeito a si mesmo, no curso de cada aula, Foucault (2010a), por assim dizer, escava os estratos de saber da fórmula grega epiméleia heautoú presente em textos filosóficos para nos mostrar que, da época antiga à Idade Moderna, a relação entre subjetividade e verdade sofreu mutações: se, para a filosofia antiga, verdade e espiritualidade eram duas questões que jamais estiveram separadas, em seu período moderno, "as condições 
segundo as quais o sujeito pode ter acesso à verdade é o conhecimento e tão somente o conhecimento. É aí que, parece-me, o que chamei de 'momento cartesiano' encontra seu lugar e sentido" (FOUCAULT, 2010a, p. 17-18).

Terceiro aspecto: a monumentalização do documento e a irrupção do discurso com valor de acontecimento. Esse trabalho só é possível mediante a reconfiguração do estatuto dos documentos históricos no escopo da pesquisa arqueológica: não é o caso de reconstituir o passado a partir do que os documentos dizem, tampouco determinar se dizem a verdade. A tarefa é trabalhar o documento no interior dele próprio: recortar, distribuir, ordenar, repartir, enfim, organizar esse material, estabelecer suas séries e definir as relações entre elas. Transformam-se os documentos em monumentos, com base na descrição que destes é feita (FOUCAULT, 1972a).

Isso posto, quando empreendemos uma análise de discursos que se baliza nesses três aspectos que destaquei (relações entre séries, descontinuidade e descrição do monumento), estamos, no meu entendimento, colocando em funcionamento a ideia de que o discurso é acontecimento. Obviamente, a tarefa a ser empreendida aqui não se assemelha ao trabalho do historiador de ofício. Em relação aos processos de subjetivação, por exemplo, a finalidade é compreender por que e como se estabelecem relações entre os sujeitos e os acontecimentos discursivos, e as respostas podem levar ao entendimento sobre a sociedade atual. Segundo o que postula Foucault (2006b, p. 258), "somos inexplicavelmente ligados aos acontecimentos discursivos. Em um certo sentido, não somos nada além do que aquilo que foi dito há séculos, meses, semanas...".

Em outras publicações (NAVARRO, 2011; 2015a), discutimos os processos de subjetivação em materialidades discursivas que atualizam esses processos na mídia e na educação, tendo como norte o trabalho de "acontecimentalização" (FOUCAULT, 2006b) dos discursos. Com os avanços das pesquisas filiadas aos Estudos Discursivos Foucaultianos, a acontecimentalização torna-se um importante instrumento de leitura das séries enunciativas, visto que faz surgir uma singularidade onde a análise tradicional estaria tentada a observar uma constante histórica ou um traço antropológico imediato. Essa seria a primeira função teórico-política desse gesto de interpretação pautado na acontecimentalização.

Outro instrumento a ser adotado provoca uma "desmultiplicação causal", na medida em que possibilita analisar o acontecimento segundo processos múltiplos que o constituem. Tal é a análise que Foucault (2006b) empreende da prática do encarceramento penal como acontecimento. A desmultiplicação causal desse 
acontecimento definiu os processos de penalização, as práticas precedentes de internamento e os procedimentos comuns à justiça penal. Assim, como advoga Foucault, acontecimentalizar "é reencontrar as conexões, os encontros, os apoios, os bloqueios, os jogos de força, as estratégias etc., que, em um dado momento, formaram o que, em seguida, funcionará como evidência, universalidade, necessidade" (FOUCAULT, 2006b, p. 339).

Destaquei, até aqui, determinados aspectos, instrumentos e termos-conceituais do método arqueogenealógico, sem, necessariamente, estabelecer uma hierarquização entres eles; contudo não podemos perder de vista que a análise deve ter como ponto de chegada as regras de formação discursiva. Talvez, possa arriscar um encaminhamento metodológico inicial, a partir do qual as constantes e necessárias idas e vindas ao arquivo reclamem mais o uso de um aspecto que outro do método ou a associação de vários. A inspiração vem da introdução de A arqueologia do saber, que nos direciona para colocar, em batimento, dois gestos metodológicos inicias, acrescidos de um terceiro, que formulo em conformidade com o trajeto teórico que nos fez chegar até este ponto das reflexões:

(1) Isolar a instância do acontecimento para relacioná-lo não à atividade fundadora de um autor, de uma obra, da tradição ou espírito de época, mas a outros enunciados.

(2) Recortar uma série enunciativa para verificar as relações entre os elementos dessa série e o modo como ela significa, constrói, produz saberes sobre o acontecimento.

(3) Descrever as posições de subjetividades constituídas pelo acontecimento, interrogando a inscrição dele na superfície dos corpos.

Três gestos metodológicos iniciais impulsionados por uma importante pergunta de pesquisa: Como apareceu determinado discurso e não outro em seu lugar?

Chegamos, com isso, ao imprescindível trabalho de descrição dos discursos, vistos como

[...] práticas que formam sistematicamente os objetos de que falam. Certamente, os discursos são feitos de signos; mas o que fazem é mais que utilizar signos para designar coisas. É esse 'mais' que os torna irredutíveis à língua e ao discurso (parole). É esse 'mais' que é preciso fazer aparecer e que é preciso descrever (FOUCAULT, 1972a, p. 55). 
A pergunta geral de pesquisa e a descrição do algo a mais do enunciado nos impelem a identificar os relacionamentos que caracterizam determinada prática discursiva, assim como enfrentar as diversas e distintas instâncias de poder, quer estejam na forma de controle do acaso dos discursos (FOUCAULT 2006a,), revestidas de um poder disciplinar (FOUCAULT, 2005) ou materializadas em dispositivos de segurança (FOUCAULT, 2008), além de outros analisados por esse autor. É uma perspectiva que busca isolar e descrever a intrínseca relação entre regras de formação e estruturação do poder.

Dois exemplos dessa dinástica do poder no seu encontro com o saber e o sujeito podem ser encontrados no próprio texto da "A arqueologia do Saber" e em "A vida dos homens infames". No primeiro texto, esse encontro do poder com o saber é exposto em termos de modalidades enunciativas, em especial no discurso clínico, no qual "o médico é sucessivamente o questionador soberano e direto, o olho que observa, o dedo que toca, o órgão de decifração dos sinais, o ponto de integração de descrições já feitas, o técnico de laboratório" (FOUCAULT, 1972a, p. 59).

No segundo texto, essa dinástica funciona como algo que lança luz sobre "homens infames" esquecidos da história. Essa condição é assim descrita pelo autor: "Vidas de algumas linhas ou de algumas páginas, desventuras e aventuras sem nome, juntadas em um punhado de palavras. Vidas breves" (FOUCAULT, 2006b, p. 203). A história desse tipo de infâmia dá visibilidade ao exercício do poder, quando seu efeito está vinculado a algum tipo de enunciado-acontecimento, tal como se constitui, a nosso ver, a chamada lettre de cachet (NAVARRO, 2018).

\subsection{Foucault confessa: tenho um método}

Eis o que encontramos logo no início de "A verdade e as formas jurídicas": "Apresentarei hoje uma reflexão metodológica para introduzir esse problema, que sob o título de A verdade e as Formas Jurídicas, pode-lhes parecer um tanto enigmático" (FOUCAULT, 2002). Logo após, segue balizando essa reflexão sobre três pontos essenciais, aos quais chama de "eixos de pesquisa".

O primeiro eixo refere-se à "pesquisa histórica", na medida em que interroga a formação de domínios de saber, a partir de práticas sociais. Foucault $(2002$, p. 8) mostra que as práticas sociais podem "engendrar domínios de saber que não somente fazem aparecer novos objetos, novos conceitos, novas técnicas, mas também fazem nascer formas totalmente novas de sujeitos e de sujeitos de conhecimento". 
No segundo, é feita uma referência explícita ao que chama de eixo metodológico, intitulado de "análise de discursos". Nesse momento, Foucault alude a pesquisas que se voltaram ao caráter linguístico dos fatos de linguagem para mostrar que o discurso, em geral, obedecia a certo número de leis ou de regularidades internas, de modo que, para ele, tais fatos de discursos não devem ser tomados somente em seu aspecto linguístico, mas também no que tange aos jogos estratégicos de ação, de reação, de pergunta e de resposta, de dominação, de esquiva e de luta. Deriva dessa posição outro conceito de discurso, visto agora como "conjunto regular de fatos linguísticos em determinado nível, e polêmicos e estratégicos em outro. Essa análise de discurso como jogo estratégico e polêmico é, a meu ver, um segundo eixo de pesquisa" (FOUCAULT, 2002, p. 9).

O terceiro eixo de sua pesquisa consiste em uma reelaboração da "teoria do sujeito", nos seguintes termos:

Seria interessante tentar ver como se dá, através da história, a constituição de um sujeito que não é dado definitivamente, que não é aquilo a partir do que a verdade se dá na história, mas de um sujeito que se constitui no interior mesmo da história, e que é a cada instante fundado e refundado pela história (FOUCAULT, 2002, p. 10).

Ao término de toda essa exposição, considero dispor de alguns elementos conceituais para concluir esta seção, direcionando o esforço argumentativo para a ideia de discurso como prática que forma seus objetos e as implicações desse postulado para a análise de discursos que realizamos na linha de Estudos Discursivos foucaultianos.

Para tanto, procuro convergir, para essa concepção de discurso como prática, passagens retiradas ainda de "A arqueologia do Saber"com outras de "A verdade e as formas jurídicas", visto que elas celebram o encontro do saber com o poder.

Em “A verdade e as formas jurídicas”, a figura que promove isso é Nietzsche e sua crítica à crença na origem, ao propor a ideia de Erfindung, palavra alemã para designar invenção, fabricação. Foucault (2002) menciona dois exemplos dados por esse filósofo: a fabricação da religião e a da poesia.

Foucault vai a Nietzsche para assentar a ideia de que "a religião não tem origem, não tem Ursprung, ela foi inventada, houve uma Erfindung da religião. Em um dado momento, algo aconteceu que fez aparecer a religião. A religião foi fabricada. Ela não existia anteriormente" (FOUCAULT, 2002, p. 15). Ainda acompanhando Nietzsche e a ideia de Erfindung, relata que, em dado momento histórico, ocorreu a alguém utilizar algumas propriedades rítmicas ou musicais da linguagem para falar, para impor 
suas palavras ou para estabelecer, por meio delas, algum tipo de poder sobre outras pessoas. "Também a poesia foi inventada ou fabricada" (FOUCAULT, 2002, p. 15).

Essa Erfindung, essa invenção, é, para Nietzsche, por um lado, uma ruptura, por outro, algo que "possui um pequeno começo, baixo, mesquinho, inconfessável" (FOUCAULT, 2002, p. 17). Vale lembrar que nem todos os acontecimentos são grandiosos ou impactantes. Segue dizendo que "foi por obscuras relações de poder que a poesia foi inventada. Foi igualmente por puras obscuras relações de poder que a religião foi inventada". Assim, "O conhecimento foi, portanto, inventado", conclui Foucault (2002, p. 18).

No que tange ao conhecimento, há somente rupturas, relações de dominação e de subserviência, enfim, relações de poder; com isso, vemos desaparecer o sujeito, concebido em sua soberania e em sua unidade, aparecendo, em seu lugar, as modalidades enunciativas que são definidas pelas práticas discursivas.

O que é, pois, a prática, senão aquilo que os homens fazem? Nada de enigmático! A prática discursiva constitui o lugar onde os objetos se formam ou se deformam, onde aparece ou se apaga uma pluralidade emaranhada de objetos de discurso. Assim, analisar um discurso é fazer aparecer um conjunto de regras próprias a uma prática discursiva, sem a tarefa de encontrar as origens dos discursos, mas os começos possíveis de serem demarcados.

$\mathrm{Da}$ “A arqueologia do Saber”, faço um recorte a partir da prática discursiva psiquiátrica no que tange à formação de seus objetos de discurso:

Se, em nossa sociedade, em uma época determinada, o delinquente foi
psicologizado e patologizado, se a conduta transgressora pôde dar lugar a
toda uma série de objetos de saber, deve-se ao fato de que, no discurso
psiquiátrico, foi empregado um conjunto de relações determinadas. Relação
entre planos de especificação [...] e planos psicológicos de caracterização [...]
Relação entre a instância de decisão médica e a instância de decisão
judiciária [...] Relação entre o filtro constituído pela interrogação judiciária
[...] e o filtro constituído pelo questionário médico [...] Relação entre as
normas familiares [...] e o quadro de sintomas patológicos [...] São essas
relações que, atuando no discurso psiquiátrico, permitiram a formação de
todo um conjunto de objetos diversos (FOUCAULT, 1972a, p. 49).

A experiência de lidar com as questões de método aqui expostas (sempre em parceria com os integrantes do GEF) vem configurando um percurso teórico-analítico que, resumidamente, delineio, a partir de pesquisas em desenvolvimento sobre a velhice, já citadas na seção 2.2.

Uma vez realizado o trabalho de acontecimentalização e de desmultiplicação causal a respeito dos discursos que produzem o objeto velhice, as análises têm 
permitido vislumbrar a constituição de uma "árvore de derivação enunciativa" (FOUCAULT, 1972), por intermédio da qual identificamos, por exemplo, a formação do discurso das novas tecnologias e das medicinas nutricional e estética. A análise coloca, junto à raiz dessa árvore enunciativa, funcionando como enunciados reitores, aqueles que se referem a toda uma rede de saberes da qual participam instituições de ensino, programas de medicina preventiva, nutricional e estética, campanhas de retardamento do envelhecimento, programas de incentivo cultural e de cultura física, planos de seguridade, entre outros.

No curso do florescimento dessa árvore, encontram-se elementos discursivos desses campos sendo incorporados aos saberes sobre os sujeitos da terceira e quarta idades; por fim, nas extremidades dos ramos, a emergência da subjetividade "melhor idade". É importante ressaltar aqui que a constituição de uma árvore enunciativa não tem por meta encontrar o momento de origem de uma dada positividade, mas estabelecer as formas específicas de um acúmulo.

A análise segue em busca de especificar a existência de uma regularidade na dispersão desses acontecimentos e sua recorrência enunciativa. Como ensina Foucault (1972a, p. 163), a regularidade designa, na análise arqueológica, "o conjunto das condições nas quais se exerce a função enunciativa" que assegura e define a existência dos enunciados. Ainda tomando como exemplo o objeto idoso, tal como esse é posicionado em sites e em blogs a ele endereçados, vemos configurar-se uma prática discursiva de subjetivação que se encontra vinculada aos dispositivos de poder-saber tecnológicos, os quais impõem a esse sujeito o desenvolvimento de certas habilidades, tais como: ligar seu computador, saber navegar pelos sites que possam ser de seu interesse, fazer download de vídeos, instalar dispositivos, como câmeras de vídeo para, se possível, interagir com outras pessoas de seu convívio familiar ou amigos. Essa prática discursiva requer um corpo que, embora envelhecido, tenha controle, autonomia e regulação de ações que venham a ser requeridas para a interação com o meio digital.

Como observado em outra situação (NAVARRO, 2015b), a prática discursiva da $w e b$, devido ao fato de estar sustentada pelo dispositivo de poder das tecnologias de informação, estabelece a distinção entre o "velho velho" e o "novo velho". Assim, coloca, à margem desse dispositivo, os sujeitos que não fazem uso dos recursos da web, ao mesmo tempo em que dá visibilidade aos novos corpos velhos que se sujeitam a esse mesmo dispositivo. $\mathrm{O}$ "novo velho" é aquele cujo corpo se adapta às novas formas de 
interação com o mundo, pela linguagem da web; e uma das formas de manifestação do exercício desse poder é fazer esse sujeito falar conforme as regras de formação discursiva da web. Essa prática faz surgir, portanto, a figura do "novo velho navegador" da internet, bem ao gosto da racionalidade neoliberal.

\section{O último Foucault ainda é um arqueologista?}

Para expressar o que intento acerca dessa outra identidade de autor, recorro, inicialmente, a Gros (2010), para quem não existe um novo Foucault, mas um projeto cuja maturação lenta o conduziria à abordagem do cuidado de si. Nessa linha de pensamento, o filósofo não abandonou seu programa de pesquisa original, menos ainda rompeu com seu modo de pensar anterior, antes, dá continuidade a eles. Dito isso, defendo a tese, nada inaugural, diga-se de imediato, segundo a qual, na dispersão do pensamento de Foucault, em suas análises distribuídas nas chamadas três fases, haveria uma regularidade que nos autorizaria a defender e nos valer da tríplice saber-poder-si, ou “combo Foucault". Essa regularidade gravitaria, pois, em torno da noção de discurso como prática que forma os objetos, os tipos de enunciação, os conceitos e os temas/estratégias de que se vale para a produção do conhecimento; tal regularidade gira, de igual modo, em torno do exercício do poder: seus efeitos, suas formas de manifestação e os modos como institui processos de subjetivação.

Isso dá suporte ao empreendimento de um projeto de análise de discursos localizado na intersecção de uma estética da existência com o dizer-a-verdade, como representado na figura 1 .

Figura 1: cuidado de si e parresía como práticas discursivas
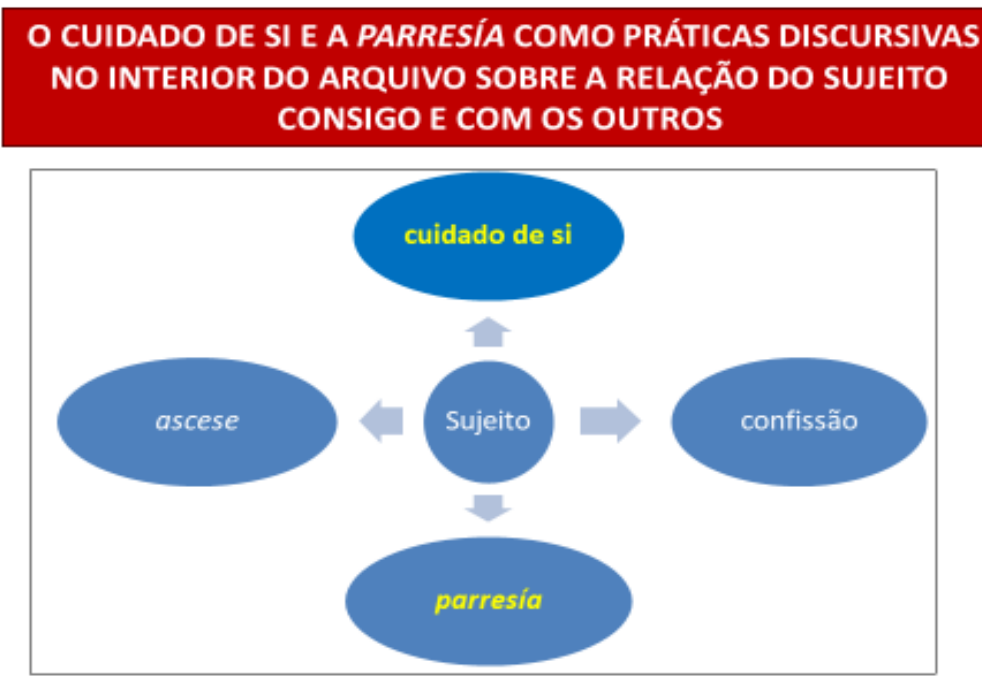

Fonte: autor do texto 
É preciso pôr em relação a cultura do cuidado de si e o franco dizer (a parresía), submetendo-os aos termos conceituais de uma arqueogenealogia, não concebida aqui como um instrumento para explicação de todos os fatos de discurso, mas para aqueles sobre os quais possamos verter nosso olhar na busca de encontrar regras de formação. Assim, diria que o cuidado de si como uma cultura e a parresía como uma atitude de governo de si e dos outros sustentam-se por meio de práticas, ao mesmo tempo em que dão condição de existência a outras tantas práticas discursivas.

Nesse viés, adentramos no pensamento desse último Foucault e dele extraímos elementos para a análise de tais práticas que, dado esse estatuto, possuem um sujeito que as assume, formam certos objetos de que falam, constituem seus conceitos e funcionam em rede. Em outras palavras, o cuidado de si e o dizer a verdade possuem seus domínios associativos, excluem certos enunciados (a retórica), elegem outros, reorganizam sentidos ditos antes. Deve haver, assim, em tese, um efeito de acúmulo, de exterioridade e de singularidade (FOUCAULT, 1972a) nos enunciados que compõem o arquivo de cujos elementos podemos nos servir para extrair o acontecimento que é o cuidado de si e a parresía no pensamento ocidental.

Sobre o fato de esses dois grandes aspectos da idade clássica serem um acontecimento, sigo atrás de rastros de uma postura arqueológica e encontro a noção de acontecimento tanto em "A hermenêutica do sujeito", quanto em "O governo de si e dos outros”. Na primeira obra, lemos a seguinte passagem, retirada da primeira hora da aula do dia 06 de janeiro de 1982:

[...] que eu gostaria de mostrar-lhes, o que eu pretendo abordar durante este ano, é essa história na qual esse fenômeno cultural de conjunto (incitação, aceitação geral do princípio de que é preciso ocupar-se consigo mesmo) constituiu, a um tempo, um fenômeno cultural de conjunto, próprio da sociedade helenística e romana (de sua elite, pelo menos), mas também um acontecimento no pensamento32. Parece-me que a aposta, o desafio que toda a história do pensamento deve suscitar está precisamente em apreender o momento em que um fenômeno cultural, de dimensão determinada, pode efetivamente constituir, na história do pensamento, um momento decisivo no qual se acha comprometido até mesmo nosso modo de ser de sujeito moderno (FOUCAULT, 2010a, p. 11).

Após a palavra pensamento, a nota de rodapé 32 remete ao uso da noção de acontecimento em trabalhos de Foucault em sua fase arqueológica, fazendo alusão, inclusive, à ideia de acontecimentalização, explicitada, também, no texto "Retornar à história" (FOUCAULT, 2005b), e às raízes nietzschianas do conceito.

Não por acaso, para introduzir as reflexões que pretende fazer no seu curso sobre "O governo de si e dos outros”, Foucault começa por estudar um texto ao qual 
confere o estatuto de epígrafe: "O que é o esclarecimento", de Kant, na aula do dia 05 de janeiro de 1983. Em determinado momento, argumenta que Kant tentará responder à questão sobre o que é atualidade ante ao acontecimento da Revolução Francesa. Desse ponto em diante, Foucault debruça-se sobre a possibilidade de a Revolução ser um acontecimento que seria sinal rememorativo, demonstrativo e prognóstico de um progresso permanente que arrasta o ser humano em sua totalidade. No entanto, como se empregasse a ideia de acontecimentalização cunhada em sua fase arqueológica, mas sem mencionar esse conceito, pede aos seus alunos que prestem mais atenção a Kant, pois

[...] não é nos grandes acontecimentos que devemos buscar esse sinal que será rememorativo, demonstrativo e prognóstico do progresso. É em acontecimentos quase imperceptíveis. Quer dizer que não é possível fazer essa análise do nosso presente em seus valores significativos sem se entregar a uma hermenêutica ou a uma decifração que permitirá dar, ao que aparentemente não tem significação nem valor, a significação e o valor importantes que buscamos [...] O significativo é a maneira como a Revolução faz espetáculo, é a maneira como é recebida em toda a sua volta por espectadores que não participam dela, mas a veem, que assistem a ela e que, bem ou mal, se deixam arrastar por ela [...] O importante na Revolução, portanto, não é a própria Revolução, que, de todo modo, é um desperdício, mas o que acontece na cabeça dos que não fazem a Revolução, ou em todo caso que não são seus atores principais (FOUCAULT, 2010b, p. 18-19).

Como representado na figura 1, a cultura do cuidado de si e a parresía teriam, pois, seus regimes de enunciação e seriam, de igual modo, da ordem das instituições (o bom governante, para Antiguidade Clássica, é aquele sujeito cuidadoso de si e que assume os riscos da fala franca). Somos levados, assim, a interrogar a espessura material dos discursos do cuidado de si e da parresía. Um olhar arqueológico encontrará, em Foucault, indícios de que ele assim procede, perseguindo os estratos históricos em que, de um lado, a fórmula grega epiméleia heautoû tem condições de emergência e de circulação, e de outro lado, os enunciados confessionais configuram a estrutura pragmático-filosófica da imperiosa necessidade de dizer toda a verdade de si para o bom governo dos vivos.

É um saber que se forma em torno de uma estética da existência e em torno da verdade. Aludindo ao texto Foucault, de Deleuze (2008), podemos advogar a favor da ideia de que o saber do cuidado de si e o saber do dizer a verdade são combinações do visível e do enunciável próprias a cada estrato de determinada formação histórica. Se cada estrato se configura em torno daquilo que se pode ver e daquilo que se pode dizer 
em uma determinada época, teremos o visível e o enunciável dos cuidados de si hoje e o visível e o enunciável do dizer-a-verdade também hoje. Cartografar tais formas de saber demanda extrair dos acontecimentos discursivos o que se pode ver e dizer em termos de cuidado consigo e com os outros e o que se pode ver e dizer no que concerne à verdade, considerando as mudanças em seus regimes.

Cuidado de si e parresía também dão visibilidade a um tipo específico de poder exercido em textos filosóficos e em tragédias da Antiguidade Clássica. O estudo do poder permitiu a Foucault recusar a ideia de que a liberdade seria aquela concedida via aparato jurídico-político do poder. Ao olhar o poder e suas técnicas, são outras as condições nas quais o indivíduo emerge, visto que isso se dá pelo acontecimento do encontro do poder com as artes da existência, donde a tese segundo a qual o poder só se exerce onde há liberdade (FOUCAULT, 1995).

De que poder estou tratando aqui e como observá-lo na emergência e na circulação do cuidado de si e da parresía? Para responder, vou retomar a definição de discurso como prática, apresentada em "A arqueologia do Saber” e já exposta aqui na seção 2.2, da qual dou novamente atenção ao "mais que é preciso fazer aparecer e que é preciso descrever" (FOUCAULT, 1972a, p. 55). Se quisermos nos valer da ideia de Erfindung, diremos que não existe, previamente, esse sujeito cuidadoso de si e parresiasta. Ele foi "fabricado" nos textos de filósofos da Antiguidade Clássica, e o "mais" que a análise desses regimes de práticas deve fazer aparecer é o poder que se almeja.

Na cultura do cuidado de si, mais precisamente em "Alcebíades", de Platão, aparece, como afirma Foucault, a "relação com a ação política, relação com a pedagogia, relação com a erótica dos rapazes” (FOUCAUL, 2010a, p. 69):

[...] para Sócrates, no diálogo do Alcebíades, fica claro que o cuidado de si é um imperativo proposto àqueles que querem governar os outros, e em resposta à questão 'como se pode bem governar?'. Cuidar de si é um privilégio dos governantes ou, ao mesmo tempo, um dever dos governantes, porque eles têm que governar. Será interessante ver como esse imperativo do cuidado de si de certo modo vai generalizar-se, tornar-se um imperativo, um imperativo 'para todo o mundo', mas, desde logo, colocando 'todo mundo' entre aspas (FOUCAULT, 2010a, p. 69).

Ainda em "Alcebíades”, estar ocupado consigo é uma condição para uma ação política definida, que é o governo efetivo da cidade. Foucault diz: "Não se pode governar os outros, não se pode bem governar os outros, não se pode transformar os 
próprios privilégios em ação política sobre os outros, em ação racional, se não se está ocupado consigo mesmo" (FOUCAULT, 2010a, p. 35).

Por sua vez, a prática do dizer-a-verdade, no exercício de um bom governo dos vivos, é, ao mesmo tempo, uma virtude, um dever e uma técnica; faz parte dos procedimentos de governo e participa da transformação do indivíduo em sujeito de uma ética que lhe garante o direito legítimo de governar. Nessas práticas, pelo fato de o poder se encontrar implicado na relação entre o parresiasta e aqueles a quem a fala franca se dirige,

[...] sempre há parresía quando o dizer-a-verdade se diz em condições tais que o fato de dizer a verdade, e o fato de tê-la dito, vai ou pode ou deve acarretar consequências custosas para os que disseram a verdade [...] Em outras palavras, dizer a verdade na presença de Dionísio, o tirano que fica furioso, é abrir para quem diz a verdade um certo espaço de risco, é abrir um perigo, é abrir um perigo em que a própria existência do locutor vai estar em jogo (FOUCAULT, 2010b, p. 55, grifo nosso).

A questão do risco que ronda os que têm a coragem da verdade é um dado importante que qualifica a singularidade de uma enunciação parresiástica. De acordo com Foucault (2011), aquele que tem a coragem da verdade pode enfrentar o risco de ferir o outro, deixá-lo com raiva ou, até mesmo, provocar condutas de extrema violência. A chamada "cultura do cancelamento" é uma forma contemporânea de fazer aquele que diz sua verdade cair no ostracismo, algo bastante perigoso, visto que uma forma de se sentir vivo, hoje, é ter seguidores e curtidas nas postagens feitas nas redes sociais.

\subsection{Por uma arqueogenealogia da subjetividade e da verdade}

Foucault (2010a) problematiza a questão da hermenêutica de si não apenas por suas formulações teóricas, mas em relação a um conjunto de práticas que tiveram uma grande importância na Antiguidade Clássica e tardia. Como já visto, o ponto de partida é um estudo dedicado ao cuidado de si, em "Alcebíades", em que se verificam quatro modos de realização da fórmula epiméleia heautoû: Alcebíades é convencido de que deve ocupar-se consigo; é definido para ele aquilo com o qual se deve ocupar (a alma); é ensinado a como fazer para dela se ocupar, ou seja, voltando o olhar para o Divino, onde se acha o princípio da sabedoria; em seguida, é dito a Alcebíades qual a finalidade dessa prática: o governo da cidade, sendo que o governo dos outros passa pelo governo de si (do cuidado com a alma). 
Na noção de cuidado de si, encontra-se implicado todo um corpus definindo uma maneira de ser, uma atitude, formas de reflexão que constituem uma espécie de fenômeno extremamente importante na história das práticas de subjetividade. A cultura do cuidado de si se exerce por meio de uma série de práticas designadas, geralmente, pelo termo ascese, as quais tinham por função transformar o sujeito em objeto de saber possível a partir de práticas de si, tais como: técnicas de meditação, memorização do passado, exame de consciência e verificação das representações. Essa cultura de si comportava, portanto, discursos que auxiliariam os indivíduos a se despirem de identidades impostas e a se transfigurarem, encontrando outras formas de viver. Eis, pois, a relação indissociável entre verdade e subjetividade. Considerando o exposto, podemos acrescentar à pergunta arqueológica "por que este enunciado e não outro em seu lugar?" outra, formulada no interior da ética e da estética da existência: "a partir de quais regras de conduta (práticas discursivas), mediadas pelo cuidado de si, os sujeitos se constituem como tal?

No que tange às questões de governo, Foucault (2010b) analisa a tragédia "Íon", de Eurípedes, qualificando-a como um texto que funda o dizer-a-verdade na sociedade ateniense e instaura o que chama de "dramática do discurso verdadeiro" na pólis. Em síntese, Creusa, filha de Erecteu, que é um ateniense de pura cepa, é seduzida e possuída por Apolo nas grutas da Acrópole (lugar sagrado reservado para o culto de Atena). Dessa relação, nasce Íon, que é abandonado pela mãe e levado por Hermes, a mando do próprio Apolo, para servir no templo deste deus, em Delfos. Creusa, por sua vez, é casada com Xuto, imigrante que ajudou Erecteu na guerra.

A peça vai consistir em que o servidor anônimo do templo de Apolo vai se revelar não uma criança anônima encontrada em Delfos, mas alguém que, concebido em Atenas, nascido em Atenas, vai poder voltar a Atenas e consumar a missão histórica e política de reorganização da cidade, melhor ainda: de fundação dessa longa dinastia humana que são os iônios (FOUCAULT, 2010b, p. 76).

Em "Íon”, há a série dos três "dizer-a-verdade”: do oráculo, da confissão e do discurso político. É o que Foucault qualifica como "dramática do discurso verdadeiro": a representação dramática do fundamento do "dizer-a-verdade" política no campo da constituição ateniense e do exercício do poder em Atenas. Íon só poderá reintegrar-se a Atenas se souber que é filho de uma ateniense, no caso, de Creusa, com o deus Apolo. Somente a confissão do pai e da mãe (do deus e da mulher) poderá fazer que Íon exerça seu direito político fundamental, qual seja, o direito de falar, de falar à cidade, de dirigir 
à cidade uma linguagem de verdade e uma linguagem de razão. A relação entre a verdade sobre a paternidade de Íon e a arte de governar a cidade está vinculada ao falar francamente, pelo ato da confissão de Creusa e de Apolo.

Feita essa exposição de método, desenvolvo uma proposta de análise nos termos aqui discutidos acerca do tema aborto, tal como ele ganha visibilidade em uma matéria de capa da Revista $V_{e j a}{ }^{4}$, de 1997.

A análise tem como foco as condições de possibilidade de um discurso confessional sobre o aborto por mulheres que o praticaram. Um primeiro ponto a considerar é que, em 1997, ocorre a aprovação, pela Comissão de Constituição e Justiça da Câmara dos Deputados, da regulamentação do aborto legal. A partir disso, começa-se a configurar a acontecimentalização desse tema em vários meios de comunicação em circulação à época: a prática do aborto entra novamente nas agendas de discussões políticas, jurídicas, religiosas, educacionais, midiáticas etc. Entre os discursos que, novamente, trabalham esse acontecimento, o de cunho noticioso tem seu momento de maior visibilidade na capa da Revista Veja desse mesmo ano.

Figura 2: Imagens de mulheres que fizeram aborto

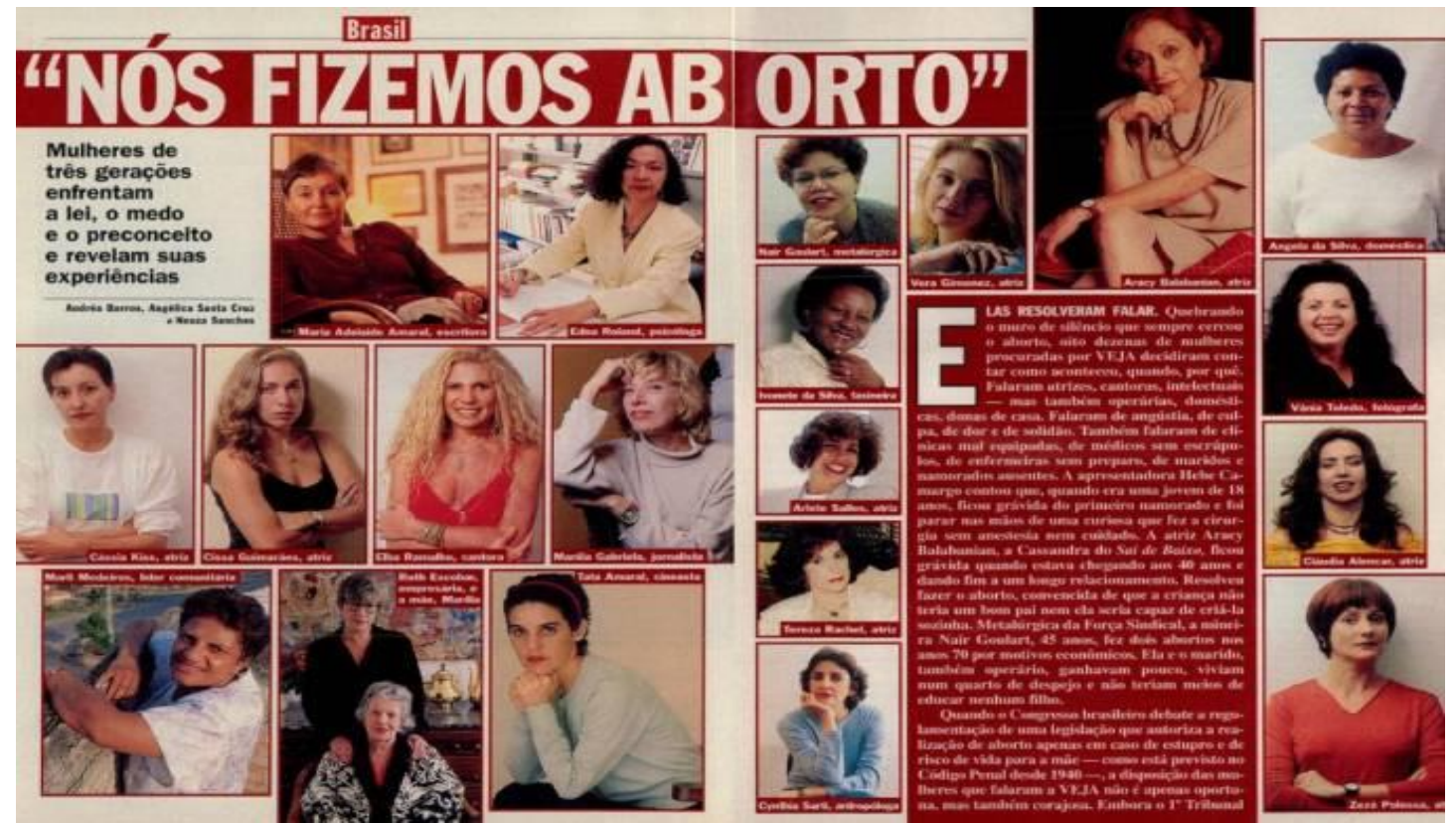

Fonte: Revista Veja, 1997

Elementos dessa prática discursiva nos permitem identificar, na figura 2, a produção de um efeito parresiástico sobre o aborto. Lembramos que, em “Íon”, de Eurípedes, Creusa fala em uma cena de confissão dupla, a saber, confissão acusadora

\footnotetext{
${ }^{4}$ BARROS, Andréa; CRUZ, Angélica Santa; SANCHES, Neuma. "Nós fizemos aborto". Veja, p. 26-33, 17 set. 1997.
} 
contra o deus Apolo, pai de Íon, e confissão de certo modo humana, penosamente arrancada palavra por palavra. Na reportagem, entram em jogo:

1) o interrogatório, cujo efeito é fazer as mulheres falarem sobre o aborto. A finalidade desse procedimento de extração da verdade é que a fala confessional entre no jogo estratégico de poder, podendo exercer uma ação sobre a pólis (o governo dos outros como personalidades, celebridades, trabalhadoras que são);

2) a confissão das mulheres atravessada pelo dispositivo da maternidade (as expressões e as escolhas lexicais diretamente relacionadas ao contexto em que se dá a reportagem);

3) instaura-se uma relação entre verdade (a prática do aborto) e subjetividade (as mulheres que são personalidades, celebridades, trabalhadoras e mães), e isso se manifesta pelo exame de consciência que fazem quando relatam essa experiência e os traumas decorrentes dela.

Tais elementos de regularidade discursiva nos indicam a formação de uma dramática do discurso verdadeiro, que é apreendida pelo exame do estatuto de quem fala (atrizes, cantoras, escritoras, ativistas políticas e mulheres do povo), da posição que o sujeito confessional ocupa (visto que o acesso à verdade sobre o aborto passa pelo ato de confissão pública) e da modalidade enunciativa jornalística. Essa confissão é interpretada por aquele que a acolhe, ou seja, o enunciador jornalístico; portanto é uma confissão ora relatada em terceira pessoa, ora aspeada, o que, discursivamente, separa o relato jornalístico da parresía que nele se manifesta; as mulheres parresiastas se dirigem a outras mulheres, que talvez tenham passado por essa mesma situação; possivelmente, dirigem-se, também, aos que fazem as leis no país.

Podemos, ainda, destacar outros elementos discursivos que sinalizam as regras de formação dessa dramática do discurso verdadeiro na matéria da Veja (figura 2). Primeiro elemento: o fato, ou seja, o aborto praticado, como objeto de discurso; o segundo é o contar/recontar o aborto por aquelas que o praticaram, em uma enunciação confessional; terceiro elemento: mostrar/interpretar o fato ocorrido no passado com um olhar impregnado do presente, por que nem esteve lá (a posição de sujeito jornalista); quarto: a reconstituição das lembranças em uma arquitetura textual dolorosa (o dizível), que acaba por ratificar o discurso da culpa (o enunciável), em virtude do dispositivo da maternidade que atravessa as mulheres que confessam; quinto elemento: o discurso de Veja serve de suporte para a apropriação cotidiana de valores, por parte do leitor, em uma tentativa de compreensão do mundo, o que põe em circulação o governo dos outros 
pelo governo de si; sexto e último elemento dessa regra de formação: cada mulher, no ato de sua confissão, participa da construção do discurso noticioso, que as posiciona como protagonistas de um fato. Em síntese, a dramática desse discurso parresiástico em funcionamento dá visibilidade ao processo de subjetivação dessas mulheres.

\section{CONSIDERAÇÕES FINAIS}

O esboço de descrição e de compreensão das práticas discursivas de subjetivação da velhice, da parresia e do cuidado de si, com base no quadro teórico apresentado, permite que façamos uma leitura discursiva dos enunciados, para deles identificar as regras de formação de tais práticas, as posições de sujeito que fala no interior desse discurso, a regularidade e a recorrência enunciativas, o que nos possibilitou compreender as condições nas quais se exerce a função enunciativa que assegura e define essas práticas do cuidado e da verdade e os dispositivos de saber/poder postos em funcionamento nos processos de subjetivação.

Esse esboço teve por objetivo, também, iluminar tantas outras reflexões que têm por finalidade compreender o "como" do poder, isto é, as formas pelas quais o poder se exerce sobre os corpos e o seu contraponto, que são as práticas de liberdade, pois, como postula Foucault (2010a), o cuidado de si é condição para governo dos vivos.

Pesquisas dessa envergadura inserem-se no campo teórico dos Estudos Discursivos foucaultianos, estando respaldadas por um movimento de incursão no interior do conjunto dos trabalhos de Michel Foucault, o qual conduzirá o analista por um caminho que vai da arqueologia, passando pelas relações de poder, até adentrar o campo da estética da existência, sem perder de vista a descrição do discurso com valor de acontecimento no interior dos diferentes jogos de poder-saber-si.

\section{REFERÊNCIAS}

BAZZA, A. Ser idoso na atualidade: subjetividade e discurso. Guarapuava: Editora Unicentro, 2018.

BAZZA, A. B.; NAVARRO, P. Discursos sobre o idoso: sexualidade e subjetividade. In: Linguagem em (Dis)curso - LemD, v. 19, n. 2, p. 293-309, 2019.

DE CERTEAU, M. A invenção do cotidiano I: as artes do fazer. Petrópolis: Vozes, 1994.

COURTINE, J-J. Le tissu de la mémoire: quelques perspectives de travail historique dans les sciences du langage. In: COURTINE, Jean-Jacques (org.). Mémoire, histoire, langage. Langages, n. 114, Paris: Larousse, 1994.

DELEUZE, G. Foucault. 2. ed. Buenos Aires: Paidós, 2008.

DOSSE, F. A história à prova do tempo: da história em migalhas ao resgate do sentido. São Paulo: Editora Unesp, 2001. 
FOUCAULT, M. A arqueologia do saber. Tradução de Luiz Felipe Baeta Neves. Petrópolis: Vozes; Lisboa: Centro do Livro Brasileiro, 1972a.

FOUCAULT, M. História da loucura na Idade Clássica. São Paulo: Perspectiva, 1972b.

FOUCAULT, M. Microfísica do poder. Organização e tradução de Roberto Machado. Rio de Janeiro: Edições Graal, 1979.

FOUCAULT, M. História da sexualidade 2: o uso dos prazeres. Tradução de Maria Thereza da Costa Albuquerque. Rio de Janeiro: Edições Graal, 1984.

FOUCAULT, M. História da sexualidade 1: a vontade de saber. Tradução de Maria Thereza da Costa Albuquerque e J. A. Guilhon Albuquerque. Rio de Janeiro: Edições Graal, 1988.

FOUCAULT, M. O Sujeito e o Poder. In: DREYFUS, H.; RABINOW, P. (org.). Michel Foucault: uma trajetória filosófica para além do estruturalismo e da hermenêutica. Tradução de Vera Porto Carrero. Rio de Janeiro: Forense Universitária, 1995, p. 231-249.

FOUCAUlT, M. A verdade e as formas jurídicas. Tradução de Roberto Cabral de Melo e Eduardo Jardim Morais. Rio de Janeiro: NAU Editora, 2002.

FOUCAULT, M. Vigiar e Punir: nascimento da prisão. 30. ed. Petrópolis: Vozes, 2005a.

FOUCAULT, M. Retornar à história. Ditos \& Escritos II. Rio de Janeiro: Forense Universitária, 2005b, p. 282-295.

FOUCAUlT, M. A ordem do discurso. Aula inaugural no Collège de France, pronunciada em 2 de dezembro de 1970. 13. ed. São Paulo: Edições Loyola, 2006a.

FOUCAULT, M. Estratégia, poder-saber/Michel Foucault. Coleção Ditos \& Escritos IV. Organização e seleção de textos de Manoel Barros da Motta; tradução de Vera Lúcia Avellar Ribeiro, 2. ed. Rio de Janeiro: Forense Universitária, 2006b.

FOUCAUlT, M. A vida dos homens infames. Coleção Ditos \& Escritos IV. Organização e seleção de textos de Manoel Barros da Motta; tradução de Vera Lúcia Avellar Ribeiro, 2. ed. Rio de Janeiro: Forense Universitária, 2006b, p. 203-222.

FOUCAULT, M. As palavras e as coisas: uma arqueologia das ciências humanas. São Paulo: Martins Fontes, 2007.

FOUCAULT, M. Segurança, território, população: curso dado no Collège de France (1977-1978). Tradução de Eduardo Brandão. São Paulo: Martins Fontes, 2008.

FOUCAUlT, M. A hermenêutica do sujeito: curso dado no Collège de France (1981-1982). Tradução de Márcio Alves da Fonseca e Salma Tannus Muchail. 3. ed. São Paulo: Martins Fontes, 2010a.

FOUCAULT, M. O governo de si e o governo dos outros: curso no Collège de France (1982-1983). Tradução de Eduardo Brandão. São Paulo: Editora Martins Fontes, 2010b.

FOUCAULT, M. A coragem da verdade. São Paulo: Martins Fontes, 2011.

FOUCAULT, M. O corpo utópico, as heterotopias. Tradução de Selma Tannus Muchail. São Paulo: Edições N-1, 2013.

GROS, F. "Situação do curso". In: FOUCAULT, M. A Hermenêutica do sujeito. São Paulo: Martins Fontes, 2010a, p. 455-493.

KUHN, T. S. A estrutura das revoluções científicas. São Paulo: Perspectiva, 2013.

MACHADO, R. Ciência e saber: a trajetória da arqueologia de Michel Foucault. 2. ed. Rio de Janeiro: Edições Graal, 1988.

MALDIDIER, D.; GUILHAUMOU, J. La mémoire et l' événement: le 14 juillet 1989. In: COURTINE, J-J (org.) Mémoire, histoire, langage. Langages, n. 114, Paris: Larousse, jun. 1994.

NAVARRO, P. Práticas discursivas de subjetivação: dispositivos de análise. In: PIOVEZANI, C.; CURCINO, L.; SARGENTINI, V. (org.). Discurso, semiologia e história. São Carlos, SP: Claraluz, 2011, p. 269-292.

NAVARRO, P. Por uma análise arqueogenealógica do discurso. In: BARONAS, R. L. (org). Estudos discursivos à brasileira: uma introdução. Campinas, SP: Pontes Editores, 2015a, p. 149-173. 
NAVARRO, P. Dispositivo e governo da velhice no discurso da web. Revista da Abralin, vol. 14, n. 2, p. 193-214, 2015b.

NAVARRO, P. Acontecimento discursivo e efeitos de poder sobre o sujeito idoso. In: BUTTURI JÚNIOR, Atílio; SEVERO, Cristine Gorski. Foucault e as linguagens. Campinas, SP: Pontes Editores, 2018, p. 267-296.

NORA, P. Les lieux de mémoire. Paris: Gallimard, 1985.

NORA, P. Entre memória e história: a problemática dos lugares. Tradução de Yara Aun Khoury. In: Projeto História. São Paulo, n. 104, 1993.

PÊCHEUX, M. A análise de discurso: três épocas. In: GADET, F.; HAK, Tony (org.). Por uma análise automática do discurso: uma introdução à obra de Michel Pêcheux. Tradução de Jonas de A. Romualdo. Campinas, Ed. da Unicamp, 1990a, p. 311-318.

PÊCHEUX, M.; FUCHS, C. A propósito da análise automática do discurso: atualização e perspectivas. In: GADET, F.; HAK, T. (org.). Por uma análise automática do discurso: uma introdução à obra de Michel Pêcheux. Tradução de Bethânia Mariani et alii. Campinas: Editora da Unicamp, 1990b, p. 163252.

POLLA, D. Dispositivos e práticas cotidianas de existência da terceira idade em instituições maringaenses. Tese (Doutorado em Letras). Programa de Pós-Graduação em Letras - Universidade Estadual de Maringá. Maringá-PR, 2018. Disponível em: http://www.ple.uem.br/defesas/pdf/dpolla_do.pdf. Acesso em: 15 nov. 2020.

SANCHES, H. O.; NAVARRO, P. Discurso e memória no espaço institucional do asilo para idosos. In: Revista Interfaces, vol. 10/n.3, 147-159, 2019.

VEYNE, P. Como se escreve a história: Foucault revoluciona a história. Tradução de Alda Baltar e Maria Auxiliadora Kneipp. 4. ed. Brasília: Editora Universidade de Brasília, 1998. 